\title{
Stimulus intensity and the magnitude of the licking reflex in rats'
}

STEWART H. HULSE

THE JOHNS HOPKINS UNIVERSITY

The number of tongue licks elicited in rats by a single drop of water was measured as a function of the volume of the drop. The typical response pattern was a single burst of licks which increased in size as drop size increased. The data add to the notion that licking in rats is an elicited reflex with volume of fluid touching the tongue representing an intensity parameter of the eliciting stimulus.

There are now a number of suggestions in the literature that tongue licking in rats has many of the characteristics of an elicited reflex. DeBold, Miller, \& Jensen (1965) and Patten \& Deaux (1966), for example, have shown that the response can be classically conditioned, while Snyder \& Hulse (1961) have shown that the response exhibits fatigue in the sense that rate of licking during bursts decreases as the rat makes more and more licks in a session of drinking. Snyder and Hulse also showed that rate of licking in bursts increases as the size of the drop of fluid obtained with each lick increases.

The purpose of this experiment was to identify one of the intensity parameters of the stimulus which elicits the licking reflex. Three assumptions were made: (a) fluid touching the tongue is an adequate stimulus for the reflex, (b) the number of licks elicited in a burst by one drop of fluid is a proper measure of the magnitude or "size" of the reflex, and (c) the magnitude of the reflex will increase as the size of the drop of fluid increases, i.e., that the volume of a drop of fluid is an index of its intensity as an eliciting stimulus.

Method

The Ss were six female rats of the Sprague-Dawley strain, 154 days of age at the time the experiment started. They had been used previously in a runway study involving hunger drive and food reward. The Ss were tested in a box, 4.5 in. wide, 9 in. long, and 6.5 in. deep. One end of the box was made from Plexiglas into which a $1-\mathrm{cm}$ by $2-\mathrm{cm}$ vertical slot was cut, 2 in. above the grid floor. A brass tube, $3 / 16$ in. in outside diameter, protruded through the slot so that its flat tip was flush with the interior edge of the slot. The tube had a tiny (No. 79 drill) fluid hold in its center. A guillotine door located inside the box, $0.5 \mathrm{in}$. in front of the tube, let $\mathrm{E}$ control access to the tube. Drops of fluid of specified volume could be pumped through the tube with an infusion pump (Hulse, 1960) where surface tension held them to the face of the tube. Licks on the tube were recorded by means of an electronic relay which drove an Esterline Angus event recorder.

The Ss were placed on a schedule of water deprivation ( $1 \mathrm{hr}$. free access to water following the daily treatment) and adjusted to the apparatus during four days of pretraining. Each day, S was placed in the box and permitted 10 5- to 15-sec. sessions of drinking, spaced about 30 sec. apart, from an ordinary laboratory water bottle and drinking tube. The $\mathrm{E}$ held the tube through the slot and controlled access to it with the guillotine door. At the end of this time, all Ss came to the tube and drank just as soon as the door was opened. Six days of testing followed pretraining. Each day, each $S$ was placed in the box with the brass tube fixed firmly in place in the slot. The S licked 18 drops of water, one drop at a time, with an interval of about 30 sec. between the presentation of each drop. Drops of water of the following volumes were used: $.006, .010, .014, .018, .022$, and $.026 \mathrm{ml}$. The drops were presented in alternate descending (D) and ascending (A) order according to volume, with a DAD order used on Day 1, an ADA order on Day 2 , a DAD order on Day 3 , and so on. Each $S$ was thus exposed to each drop size three times each day. Results

The characteristic response to a single drop of water is a single burst of licks. Occasionally two, rarely three, bursts are seen which are separated from each other by intervals that range from 200 to $500 \mathrm{msec}$. or so, but an approach to the tube, a single burst of licks, and a retreat from the tube is the overwhelmingly predominant response pattern. Typical examples of this pattern can be seen in Fig. 1 which shows records selected from the data of three rats. Figure 1 also shows another characteristic feature of the burst: the duration of each lick and the interlick interval both tend to

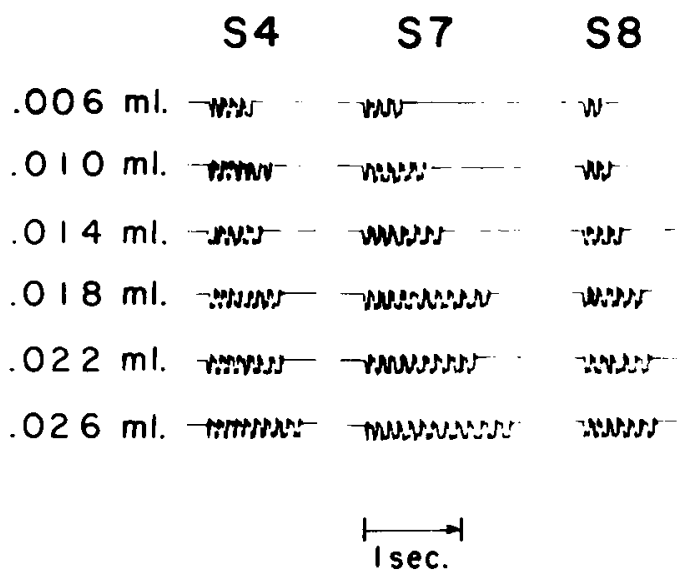

Fig. 1. Individual records showing the response to a single drop of water of varying volume. The typical response is a single burst of licks, with the number of licks in the burst increasing as drop volume increases. 


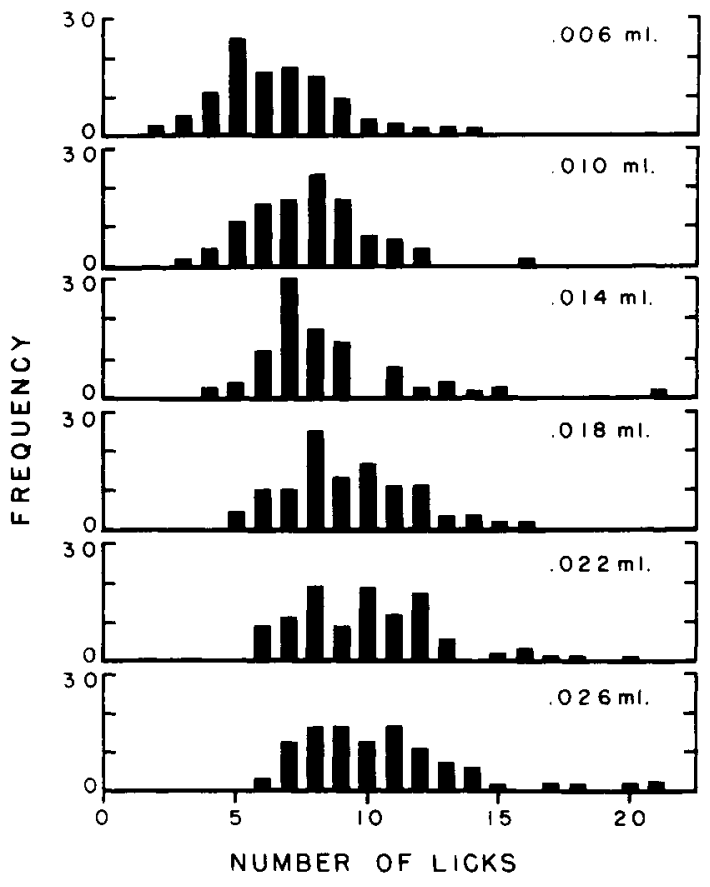

Fig. 2. Frequency distributions of burst size for drops of water of the volumes shown.

increase as the burst runs its course, particularly if the burst is a long one.

The size of the burst increases as the volume of the drop of water increases. This can be seen in the frequency distributions of Fig. 2 which are based on 18 determinations for each of the six Ss for each of the six drop sizes. The frequency distributions show a clear progression toward larger bursts as drop size increases, and there is also some indication that the distributions become flatter in the process. The overall median burst sizes for the six drop sizes, arranged in ascending order, are 5.5, 7.5, 7, 8.5, 9, and 10 licks respectively, and an analysis of variance run on medians calculated separately for each of the six Ss shows the effect of volume of drop to be highly significant $(F=$ $35.5, \mathrm{df}=5 / 71, \mathrm{p}<.001)$. There was no indication of a consistent change in the data across the six days of the experiment, nor was there any indication of differential sequence effects associated with the A or D orders of stimulus presentation.

Figure 1 also indicates that burst length increases with drop size, but the records shown in the figure are not altogether typical in this particular connection. Thus, while large drops elicited more licks than small drops most frequently in a given $A$ or $D$ sequence of drops, there were many instances in which the correlation was not perfect-as the data of Fig. 2 imply.
Nevertheless, Fig. 1 shows that a perfect correlation of drop size and burst length was obtainable within a given sequence with the present technique.

\section{Discussion}

These data add to the notion that licking in rats is, indeed, an elicited reflex once the proper stimulus has been applied to the tongue. In this connection it is important to recognize that the elicited burst of licks is just part of a total sequence of events that constitute the rat's drinking behavior, some portions of whichare clearly not elicited in the sense of an unconditioned reflex. The approach to the drinking tube and the initial touch of the tube with the tongue, for example, clearly fall into the realm of emitted behavior. But once this occurs, it appears that the behavior which ensues-the burst of licks-is largely "involuntary" under normal circumstances. Of course it is possible to introduce other-than-normal circumstances and treat licks as if they were a free operant (Hulse, Snyder, \& Bacon, 1960; Hulse \& Firestone, 1964). Under these conditions, some strange things happen-licking rate decreases as ratio of reinforcement increases, for example, a fact that might well follow on the assumption that licking is basically elicited as opposed to emitted behavior.

The results of this experiment also seem to justify the assumption that the volume of a drop of fluid is an intensity parameter of the licking reflex. In all likelihood, large drops cover a larger surface of the rat's tongue than small drops, stimulating more touch receptors in the process. At the same time, it may be that tactile stimulation is not the only dimension of the adequate stimulus for the tongue lick. An experiment incorporating drops of different concentrations of sucrose, for example, ought to show whether taste can also contribute to the intensity of the eliciting stimulus.

\section{References}

DeBold, R. C., Miller, N. E., \& Jensen, D. D. Effect of strength of drive determined by a new technique for appetitive classical conditioning of rats. J. comp. physiol. Psychol., 1965, 59, 102-. 108.

Hulse, S. H. A precision liquid feeding system controlled by licking behavior. J. exp. Anal. Behav., 1960, 3, 1-3.

Hulse, S. H., Snyder, H. L., \& Bacon, W. E. Instrumental licking behavior as a function of schedule, volume, and concentration of a saccharine reinforcer. $J$. exp. Psychol., 1960, 60, 359-364.

Hulse, S. H., \& Firestone, R. J. Mean amount of reinforcement and instrumental response strength. J. exp. Psychol., 1964, 67, 417-422.

Patten, R. L., \& Deaux, E. B. Classical conditioning and extinction of the licking response in rats. Psychon. Sci., 1966, 4, 21-22.

Snyder, H. L., \& Hulse, S. H. Effect of volume of reinforcement and number of consummatory responses on licking and running behavior. J. exp. Psychol., 1961, 61, 474-479.

\section{Note}

1. This research was supported by National Science Foundation Research Grant GB-2406. 